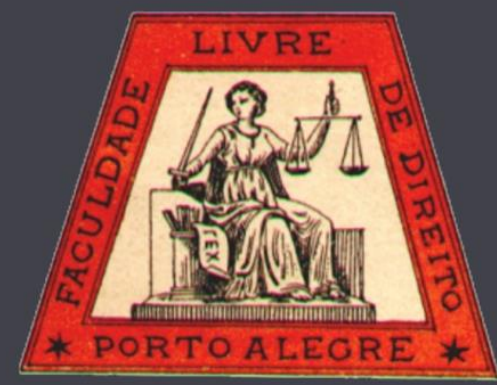

\title{
Relações contratuais paralelas
}

\author{
Parallel contractual relations
}

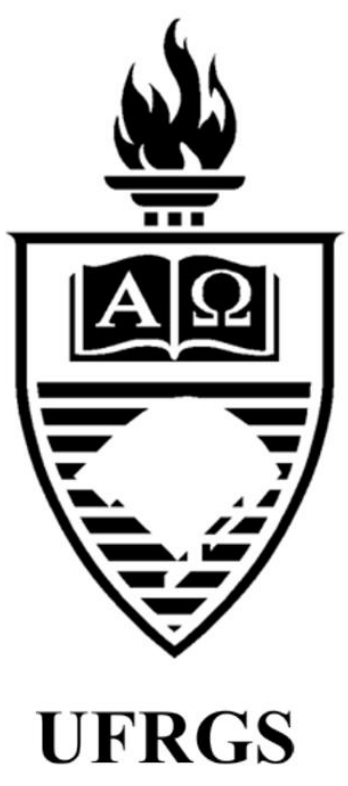

\author{
Amauri Cesar Alves
}

Universidade Federal de Ouro Preto

Revista da Faculdade de Direito da UFRGS

ISSN: 0104-6594 Site http://seer.ufrgs.br/revfacdir

Faculdade de Direito da UFRGS - Rua Riachuelo, 1317 - Centro - Porto Alegre - RS - Brasil

CEP - 90010-271 - Telefone: +55 5133083118 - Site http://www.ufrgs.br/direito/ 


\title{
Relações contratuais paralelas
}

\author{
Parallel contractual relations
}

Amauri Cesar Alves*

\section{REFERÊNCIA}

ALVES, Amauri Cesar. Relações contratuais paralelas. Revista da Faculdade de Direito da UFRGS, Porto Alegre, n. 35, p. 178-198, dez. 2016.

\begin{abstract}
RESUMO
No cotidiano do trabalho ocorrem situações em que se sobrepõem múltiplas relações jurídicas. As situações de paralelismo podem dar ensejo a dois contratos de emprego ou a dois contratos de natureza distinta, sendo, neste caso, um de trabalho (sem vínculo empregatício) e outro de emprego. Duas são as espécies do gênero relações contratuais paralelas: relações empregatícias paralelas e relações trabalhistas paralelas. A definição desenvolvida no presente estudo a respeito do paralelismo contratual tem por cerne a coexistência de dupla avença laborativa entre os mesmos sujeitos contratantes. Assim, há paralelismo contratual nas situações fáticas em que trabalhador e contratante fixam entre si dois pactos jurídicos cujo objeto é o trabalho, podendo haver entre eles dois contratos de emprego (relações empregatícias paralelas) ou um contrato de emprego e outro de trabalho sem vínculo empregatício (relações trabalhistas paralelas). Seja qual for a situação fática, juridicamente deverá o intérprete reconhecer a dupla contratação e preservar os efeitos específicos e distintos que são próprios a cada avença mantida entre os sujeitos da relação paralela.
\end{abstract}

PALAVRAS-CHAVE

Trabalho. Emprego. Paralelismo Contratual.

\begin{abstract}
In the daily work, situations occur in which multiple legal relations overlap. Parallel situations may give rise to two contracts of employment or to two contracts of different nature, being, in this case, one contract of a job (with no employment bond) and the other contract of an employment. There are two species of the genus parallel contractual relations: parallel employment relations and parallel labor relations. The definition developed in this study regarding the contractual parallelism has as its core the coexistence of dual labor agreement between the same contractual subjects. Thereby, there is contractual parallelism in factual situations where employee and contractor fix among themselves two legal agreements whose object is the work, and there may be between them employment contracts (parallel employment relations) or a contract of employment and another one of a job with no employment bond (parallel labor relations). Whatever the factual situation, the interpreter should legally recognize the dual contracting and preserve the specific and distinct effects that are specific to each agreement maintained between the subjects of the parallel relation.
\end{abstract}

\section{KEYWORDS}

Work. Employment. Contractual Parallelism.

\section{SUMÁRIO}

Introdução. 1. Relações Contratuais Paralelas na Doutrina. 2. Relações Contratuais Paralelas na Jurisprudência. 3. Relações Contratuais Paralelas no âmbito doméstico. 4. Relações Contratuais Paralelas no Magistério. Conclusão. Referências.

\section{INTRODUÇÃO}

No cotidiano do trabalho ocorrem situações em que se sobrepõem múltiplas relações jurídicas, com destaque, aqui, para as relações contratuais paralelas, que para efeito do presente estudo são aquelas em que o trabalhador mantém dupla contratação laborativa com um mesmo contratante. As situações de paralelismo podem dar ensejo a dois contratos de emprego ou a dois contratos de natureza distinta, sendo, neste caso, um de trabalho (sem vínculo empregatício) e outro de emprego.

\footnotetext{
* Doutor, Mestre e Bacharel em Direito pela Pontifícia Universidade Católica de Minas Gerais. Professor Assistente da Universidade Federal de Ouro Preto.
} 
O ordinário é que as relações de trabalho e emprego se manifestem sem se atrelar, sem se confundir e sem se apresentar em conjunto com outras relações. Assim, o trabalhador exerce, como regra geral, uma única função ${ }^{1}$ a um único empregador, em decorrência de um só contrato. $\mathrm{O}$ problema é dar soluções jurídicas a situações extraordinárias em que paralelamente à relação de emprego surgem outras pactuações.

O presente artigo, além de conceituar os institutos em debate, pretende também discorrer sobre situações fáticas específicas que envolvem professores universitários em relações paralelas com seu empregador (instituição de ensino superior privada), bem como a situação de alguns trabalhadores domésticos em paralelismo contratual.

A definição aqui apresentada a respeito do paralelismo contratual tem por cerne a coexistência de dupla avença laborativa entre os mesmos sujeitos contratantes. Assim, há paralelismo contratual nas situações fáticas em que trabalhador e contratante fixam entre si dois pactos jurídicos cujo objeto é o trabalho, podendo haver entre eles dois contratos de emprego (relações empregatícias paralelas) ou um contrato de emprego e outro de trabalho sem vínculo empregatício (relações trabalhistas paralelas). ${ }^{2}$

\footnotetext{
1 “A reunião coordenada e integrada de um conjunto de tarefas dá origem a uma função. Neste quadro, função corresponde a um conjunto coordenado e integrado de tarefas, formando um todo unitário. É, pois, um conjunto sistemático e unitário de tarefas - um feixe unitário de tarefas." DELGADO, Maurício Godinho. Curso de Direito do Trabalho. 15. ed. São Paulo: LTr., 2016. P. 1137.

${ }^{2}$ A relação de trabalho é gênero do qual a relação de emprego é espécie. Todo aquele que no mercado dispõe de sua força produtiva (ou seu saber-fazer) para proveito de outrem será considerado trabalhador. A relação de emprego é espécie de relação de trabalho que tem por sujeitos o empregado, que disponibiliza sua força produtiva, e o
}

\section{1} PARALELAS NA DOUTRINA

CONTRATUAIS

RELAÇÕES

Relações contratuais paralelas não são objeto de ampla análise doutrinária no Brasil. Maurício Godinho Delgado reconhece ser o paralelismo contratual um "fenômeno relativamente raro, embora instigante" 3 , sobretudo em âmbito celetista. Tal excepcionalidade faz com que o fenômeno não receba enfrentamento doutrinário mais amplo, embora desborde, vez ou outra, nos Tribunais Trabalhistas. Já o paralelismo doméstico parece ter recebido, historicamente, esforço doutrinário mais amplo, conforme noticia Maurício Godinho Delgado e como se depreende diretamente das obras de Alice Monteiro de Barros e Vólia Bomfim Cassar, nos termos adiante expostos.

A obra referencial sobre o tema é o "Compêndio de Direito do Trabalho", de José Martins Catharino ${ }^{4}$. O citado autor aborda o assunto em dois tópicos de sua obra. No capítulo que versa sobre "O contrato de Emprego" há um tópico denominado "Mistura contratual e sua disciplina jurídica" e no capítulo sobre "Morfologia do Contrato de emprego" há um tópico que trata de "Promiscuidade, ligação e coligação" nas relações de trabalho. $\mathrm{O}$ autor faz distinção entre contrato misto e promiscuidade contratual, sendo aquele importante para o entendimento desta.

empregador, que adquire a mão-de-obra ofertada. Permeiam tal relação jurídica elementos extraídos da realidade fática e consagrados pelo Direito (trabalho por pessoa física, pessoalidade, não-eventualidade, onerosidade e subordinação). Nem todo trabalhador é empregado, embora todo empregado seja, antes, um trabalhador. Sobre o tema, dentre outros, ALVES, Amauri Cesar. Direito do Trabalho Essencial: doutrina, legislação, jurisprudência, exercícios. São Paulo: LTr., 2013.

${ }^{3}$ DELGADO, Maurício Godinho. Curso de Direito do Trabalho. 15. ed. São Paulo: LTr., 2016. p. 614.

${ }^{4}$ CATHARINO, José Martins. Compêndio de Direito do Trabalho. São Paulo: Saraiva, 1982, vol. I 
Para Catharino, contratos mistos são aqueles "que resultam de mistura contratual de elementos ou ingredientes específicos, de dois ou mais elementos caracterizadores de contratos diferentes, normalmente isolados." ${ }^{5}$ Explica o citado autor, ainda, que "nada impede que os contratantes misturem, por ser de suas vontades e interesses, elementos de dois ou mais contratos nominados e qualificados."6

Três são as teorias, na obra de José Martins Catharino, que cuidam de disciplinar o contrato misto. São elas as teorias da abstração, da combinação e a analítica:

\begin{abstract}
A teoria da abstração, em última análise, deriva da remota e útil regra de que o acessório segue o principal, e conduz à negação do próprio "contrato misto". Analisando o contrato, verifica-se qual o seu elemento principal (prestação, para muitos) absorvente, aplicando-se-lhe as normas relativas ao negócio nominado, ao qual pertence aquele elemento. ${ }^{7}$
\end{abstract}

Tal teoria será importante para a compreensão das diversas situações fáticas que serão aqui abordadas, posto que parece ser adotada, ainda que não se faça referência direta, por juízos trabalhistas. Noutro sentido a teoria da combinação:

A da combinação, (...) constatada a pluralidade de elementos, passa-se a considerá-los cada um isoladamente, aplicando-se a cada qual as normas que lhe correspondem. Implica, portanto, divisão e desintegração do contrato, sua tomização, seu despedaçamento. ${ }^{8}$

A teoria da combinação se mostrará relevante para a análise das situações fáticas que envolvem professores universitários com dupla contratação de emprego em relação a um único empregador, pois a prática demonstra a

\footnotetext{
${ }^{5}$ CATHARINO, José Martins. Compêndio de Direito do Trabalho. São Paulo: Saraiva, 1982, vol. I, pág. 243.

${ }^{6}$ CATHARINO, ob. cit. pág. 243.

${ }^{7}$ CATHARINO, ob. cit. pág. 243.

${ }^{8}$ CATHARINO, ob. cit. pág. 243.

${ }^{9}$ CATHARINO, ob. cit. pág. 243.
}

observância isolada de direitos distintos para cada uma delas, com destaque para aqueles decorrentes de criatividade normativa autônoma (CCT, ACT).

Por fim a teoria analítica de Catharino, que sujeita a pactuação mista "às normas gerais sobre contrato, e, por analogia, às particulares relativas aos seus elementos componentes." 9 Tal teoria também poderá contribuir para a solução de diversas situações controvertidas atuais que envolvem paralelismo contratual.

Ao tratar do assunto em tela José Martins Catharino propõe ainda a caracterização de promiscuidade contratual, assim definida:

\begin{abstract}
Dá-se promiscuidade, interna ou interior, no contrato de emprego, puro ou misturado, solitário ou a outro coligado, quando o empregado, durante sua execução, trabalha sucessivamente, alternadamente, ou alternada e sucessivamente, com finalidade diversa. Tal fato ganha importância prática quando cada um dos trabalhos prestados está sujeito a intensa disciplina normativa especial, ou quando, mais ainda, um está regulado pela legislação do trabalho e outro não. ${ }^{10}$
\end{abstract}

A promiscuidade contratual acima conceituada parece identificar relações trabalhistas paralelas, o que será aqui desenvolvido nos planos teórico e prático.

Maurício Godinho Delgado também trata do assunto e compreende o paralelismo contratual como situação de "concomitância, dentro de uma mesma relação social envolvendo as mesmas pessoas, de contratos de natureza diversa, ou seja, o pacto empregatício e outro contrato de distinta natureza jurídica."11

Vólia Bomfim Cassar ${ }^{12}$ cuidou, com detalhes, da promiscuidade contratual no âmbito doméstico, tendo por fundamento de sua análise, também, a obra de José Martins Catharino.

\footnotetext{
${ }^{10}$ CATHARINO, ob. cit. pág. 277.

11 DELGADO, Maurício Godinho. Curso de Direito do Trabalho. 15. ed. São Paulo: LTr., 2016. p. 614.

12 CASSAR, Vólia Bomfim. Direito do Trabalho. 5. ed. Niterói: Impetus: 2011. p. 367-369.
} 
Destaca a autora relevantes teses para o enfrentamento das situações controvertidas decorrentes da promiscuidade, em síntese: teoria da preponderância; teoria do contágio, da alteração ou da norma mais favorável; teoria dos dois contratos e aplicação do princípio da primazia da realidade sobre a forma.

Alice Monteiro de Barros identificava a possibilidade de "serviço doméstico acumulado com serviço de atividade lucrativa", concluindo pela aplicação do "ordenamento jurídico que for mais favorável ao trabalhador"13

Francisco Ferreira Jorge Neto e Jouberto de Quadros Pereira Cavalcante tratam do tema ao analisar a possibilidade jurídica da dualidade contratual com o mesmo empregador. Entendem ser difícil, na prática, verificação da dualidade, mas admitem-na possível, lembrando que "a formação de um novo contrato exige a presença de elementos distintos do já existente" ${ }^{14}$, para que não se confunda tal figura com acúmulo ou desvio de função.

A definição aqui apresentada a respeito do paralelismo contratual tem por cerne a coexistência de dupla avença laborativa entre os mesmos sujeitos contratantes, conforme visto anteriormente. Há paralelismo contratual nas situações fáticas em que trabalhador e contratante fixam entre si dois pactos jurídicos cujo objeto é o trabalho, podendo haver entre eles dois contratos de emprego (relações empregatícias paralelas) ou um contrato de emprego e outro de trabalho sem vínculo empregatício (relações trabalhistas paralelas).

Interessante também pesquisar situações semelhantes no direito estrangeiro, com destaque aqui para concepções e experiências em Portugal e Espanha.

\footnotetext{
13 BARROS, Alice Monteiro de. Curso de Direito do Trabalho. 6. ed. São Paulo: LTr., 2010. p. 353.

14 JORGE NETO, Francisco Ferreira; CAVALCANTE, Jouberto de Quadros Pessoa. Direito do Trabalho. 6. ed. São Paulo: Atlas, 2012. p. 272.
}

Pedro Romano Martinez trata do contrato misto no Direito do Trabalho português:

\begin{abstract}
Nada obsta a que haja uma fusão entre um contrato de trabalho e outro negócio jurídico, perdendo ambos a respetiva autonomia e formando um só contrato.

(...)

Como exemplo de contrato misto pode indicar-se o contrato com porteiro de prédio de habitação; neste negócio jurídico reúnem-se regras do contrato de trabalho com normas do contrato de arrendamento. (...)

Sendo um contrato misto, o seu regime determinarse-á mediante o recurso às teorias da combinação, da absorção ou da aplicação analógica, consoante os casos. Frequentemente, como por exemplo no caso da prestação de um dos negócios jurídicos constituir uma forma, ainda que indireta, de fixação do salário, o regime do contrato de trabalho predominará e, pela teoria da absorção, a prestação do outro negócio jurídico fica sujeita ao regime laboral. ${ }^{15}$
\end{abstract}

A definição do autor português aqui citado, embora não se encaixe rigorosamente no conceito ora proposto, se assemelha à configuração de relações trabalhistas paralelas. Percebe-se a possibilidade de haver um contrato de emprego em concomitância com outro negócio jurídico que pode, pelo menos em tese, ser um contrato de trabalho sem vínculo empregatício.

O direito espanhol prevê a figura da parceria laboral, que poderia se aproximar da aqui estudada relação trabalhista paralela, pois haveria relação societária concomitante ao contrato de emprego. Ocorre que na Espanha, vistas condições específicas, prevalecerá o contrato de emprego. Eis as lições de Alfredo Montoya Melgar:

La LAR contempla una figura de aparcería - que llamamos laboral para distinguirla de la civil estricta - tan próxima al contrato de trabajo que no hay términos hábiles com los que separarla de él. Em efecto, cuando el aparcero "aporte unicamente

\footnotetext{
${ }^{15}$ MARTINEZ, Pedro Romano. Direito do Trabalho. 6. ed. Coimbra: Almedina, 2013. p. 616.
} 
su trabajo personal" y cuando su aportación de capital de explotación y circulante no alcance el 10 por 100 de su importe total, tiene garantizado el devengo del salario mínimo, y su relación jurídica com el cedente se rige por "lo previsto em la legislación laboral (se entiente que también a efectos procesales) y de Seguridad Social" (art. 30 LAR). ${ }^{16}$

Visto, portanto, que o tema desafia novas análises, interpretações e soluções, dada a sua relevância atual e diminuta expressão doutrinária, embora da lavra de importantes autores.

\section{RELAÇÕES CONTRATUAIS PARALELAS NA JURISPRUDÊNCIA.}

A jurisprudência parece revelar certa prevalência de litígios que envolvem o que aqui se denomina relação trabalhista paralela, com dupla contratação diversa, uma civilista e outra empregatícia, tendo ambas por objeto o trabalho. São situações em que uma mesma pessoa física mantém vínculos contratuais diferentes com um mesmo contratante, havendo entre eles um contrato de emprego paralelamente a uma relação de trabalho sem vínculo empregatício, fixada esta, como regra geral, nos moldes civilistas. Exemplificativamente algumas decisões proferidas em segundo grau de jurisdição trabalhista, com destaque para um vínculo civilista paralelamente a um contrato de emprego celetista:

Para se afirmar que essa prestação de consultoria fosse, em última análise, uma mera formalidade para um salário "extra-folha", teríamos que admitir a presunção de um ato ilícito, o que contraria certos princípios jurídicos, como o da boa fé existente entre os contratantes, entre outros. Não há vedação legal à coexistência de contratos diversos entre empregado e empregador paralelamente à relação empregatícia, que, certamente, pode ser a gênese daqueles. Há quem considere a hipótese de "promiscuidade contratual", nomenclatura que pode não definir com muita clareza a situação, mas nos dá a idéia do imbricamento que une os atores para além do contrato de trabalho. (TRT, $3^{\mathrm{a}}$ Região, $7^{\mathrm{a}}$ Turma, processo 0055200-26.2009.5.03.0015 RO, relator juiz convocado Mauro Cesar Silva, publicação em 03/05/2011, disponível em www.trt3.jus.br, consulta em 08/09/2016).

CONTRATO DE TRABALHO SUBORDINADO E CONTRATO DE PRESTAÇÃO DE SERVIÇOS DE TRANSPORTE RODOVIÁRIO AUTÔNOMO. MESMAS PARTES. COEXISTÊNCIA. POSSIBILIDADE. É possível a coexistência de duas relações jurídicas entre as mesmas partes, de distinta natureza, ou seja, permite-se a celebração de um contrato de trabalho subordinado e um outro de prestação de serviços autônomos, sem que isso implique na existência de um único contrato, apesar de ambos serem executados simultaneamente. Isso porque neste último ajuste não se constatou a presença dos elementos caracterizadores do liame empregatício. (TRT, $3^{\text {a }}$ Região, $7^{\text {a }}$ Turma, processo 01554-2007-030-03-00-4 RO, publicação em 01/04/2008, relatora juíza convocada Wilmeia da Costa Benevides, disponível em www.trt3.jus.br, consulta em 08/09/2016).

CONTRATOS DE TRABALHO E DE EMPREITADA. Perfeitamente válida a celebração de dois contratos distintos entre o empregado e o empregador, um de trabalho e o outro de empreitada. Importante verificar a intencionalidade das partes na contratação, a sua independência e tipos diversos de remuneração. (TRT $3^{\mathrm{a}}$ R. - 4T - RO/5240/95 - Rel. Juíza Ana Maria Valério Riccio - DJMG 08/07/1995.)

Percebe-se que em todos os três processos o TRT da $3^{\text {a }}$ Região reconheceu a multiplicidade de contratos concomitantes e deu efeitos jurídicos diversos às avenças distintas, no que aqui se denomina relações trabalhistas paralelas.

Ainda sobre relações trabalhistas paralelas algumas decisões proferidas em segundo grau de jurisdição trabalhista, com destaque para um vínculo civilista paralelamente a um contrato de emprego doméstico:

\section{VÍNCULO DE EMPREGO. EMPREGADO URBANO $\mathrm{E}$ DOMÉSTICO. PROMISCUIDADE CONTRATU}

AL. A prestação de serviços, simultaneamente, na residência do sócio e na segurança à empresa, afasta

${ }^{16}$ MONTOYA, Alfredo Melgar. Derecho del Trabajo. 34. ed. Madrid: Tecnos, 2013. p. 535. 
a caracterização do trabalhador como empregado doméstico, estando configurada a existência de vínculo de emprego diretamente com a empresa ré. Recurso provido para, reconhecendo a existência de relação de natureza empregatícia com a primeira reclamada, determinar o retorno dos autos à Origem para análise dos demais pedidos relacionados ao vínculo, de modo a evitar a supressão de instância julgadora. (TRT, $4^{\mathrm{a}}$ Região, $2^{\mathrm{a}}$ Turma, processo $\mathrm{n}$. 0000159-36.2012.5.04.0211 RO, julgamento em 18/04/2013, relator Alexandre Corrêa da Cruz, disponível em www.trt4.jus.br, consulta em 28/09/2016)

\section{PROMISCUIDADE CONTRATUAL - CONTRATO DE EMPREGO DOMÉSTICO E CONTRATO DE PARCERIA RURAL} POSSIBILIDADE E VALIDADE DESDE QUE PRESERVADAS AS CARACTERÍSTICAS EXTRÍNSECAS E INTRÍNSECAS DE CADA TIPO CONTRATUAL- Empregado doméstico é toda pessoa física, que presta serviços de natureza contínua, pessoalmente, mediante subordinação e com onerosidade, em atividade não lucrativa, no âmbito residencial, ao passo que o contrato de parceria rural é aquele em que uma pessoa cede um prédio ou um espaço rústico a outra, para ser por esta cultivado, repartindo-se os frutos entre elas, na proporção avençada. No meio rural, às vezes, pode ocorrer a mesclagem dos dois contratos, com forte e intensa predominância do contrato de emprego doméstico, uma vez que pequenas propriedades, denominadas de sítios de lazer, sem vocação para a exploração de determinada atividade econômica, permitem um pequeno plantio ou a criação acanhada de animais, com nítido e visível aproveitamento da mão de obra parcialmente ociosa do doméstico, atribuindo o proprietário ao doméstico parte da produção, para que este lhe dê a destinação que considerar mais adequada. Existem pontos de intercessão, e até de interrogação, entre os dois tipos contratuais, haja vista o objeto da prestação, que, tangencialmente e em corte horizontal, é a prestação de serviços do homem. No entanto, a aparente contradição jurídica pode ser superada, quando se atenta para as particularidades do meio rural, que se abrem em gomos e em gamas de situações variadíssimas, oriundas da superfície da realidade da convivência social, que não pode ser desprezada pelo intérprete diante de cada caso concreto. Havendo a predominância da atividade de consumo e não de produção, sem que a intenção das partes tenha sido desvirtuada pelo dador de trabalho, é possível a identificação de dois tipos de contrato, sem que haja a absorção de uma espécie pela outra. Promiscuidade contratual que se admite sem a perda das características básicas de cada espécie de contrato. (TRT, $3^{\mathrm{a}}$ Região, $4^{\mathrm{a}}$ Turma, processo $\mathrm{n}$. 00293-2009-095-03-00-2 RO, publicação em 09/11/2009, relator Desembargador Luiz Otávio
Linhares Renault, disponível em www.trt3.jus.br, consulta em 08/09/2016)

CONTRATO DE TRABALHO. DOMÉSTICO. URBANO. PROMISCUIDADE. Havendo prestação de serviços domésticos para a sócia da empresa e, também, de forma concomitante, para a atividade comercial, afigura-se a presença do contrato de trabalho promíscuo, que atrai a aplicação do princípio de proteção, consistente na regra da condição mais benéfica, no sentido de conferir ao trabalhador os direitos e vantagens oriundos do trabalho vinculado à atividade da empresa, notadamente se não há elementos para definir o período exclusivo do trabalho doméstico, daquele voltado à atividade comercial. (TRT, $3^{\mathrm{a}}$ Região, $3^{\mathrm{a}}$ Turma, processo 00272-2007-008-03-00-9 RO, relator Desembargador Cesar Machado, disponível em www.trt3.jus.br, consulta em 08/09/2016).

VÍNCULO DE EMPREGO. TRABALHO DOMÉSTICO. DIREITO AO FGTS. VIOLAÇÃO DA BOA-FÉ OBJETIVA. QUEBRA DO DEVER DE INFORMAÇÃO. Relação jurídica entre as partes mantida sob a forma de vínculo de emprego doméstico, tendo sido eventual a limpeza do escritório da empresa de propriedade da reclamada. Demanda promovida exclusivamente contra a pessoa física da empregadora, não sendo incluída no polo passivo a pessoa jurídica de que esta seria titular (escritório de corretagem de imóveis). Desempenho de atividades laborais pela reclamante na residência da demandada, sendo preponderante a sua condição de trabalhadora doméstica. Inviável, pois, o reconhecimento do vínculo na forma postulada na inicial. Devido, todavia, o pagamento dos valores informados a título de FGTS, embora não depositados na conta vinculada da trabalhadora. Configurado "venire contra factum proprium", tendo em vista a quebra de legítima expectativa criada pela empregadora doméstica ao informar à trabalhadora os valores devidos a título de FGTS nos recibos de pagamento de salários. Violação ao princípio da boa-fé objetiva, na modalidade do "dever de informação". Inteligência do art. 422 do atual Código Civil. Apelo não provido. (TRT, $4^{\mathrm{a}}$ Região, $2^{\mathrm{a}}$ Turma, processo n. 000144910.2012.5.04.0204 RO, julgamento em 22/05/2014, relator Alexandre Corrêa da Cruz, disponível em www.trt4.jus.br, consulta em 29/09/2016

Na primeira decisão citada, do TRT da $4^{\mathrm{a}}$ Região, percebe-se a ocorrência da pluralidade em razão do trabalho em residência e com finalidade econômica, mas há o reconhecimento de efeitos somente do vínculo celetista, por afastamento da possibilidade de ser doméstica a 
relação mantida. No segundo caso o paralelismo marcado por uma avença doméstica concomitante ao contrato de parceria rural, portanto autônomo. Houve o reconhecimento do paralelismo com a preservação do conteúdo jurídico próprio a cada contrato. No terceiro caso, embora se perceba a promiscuidade, a solução foi por reconhecer efeitos jurídicos de uma só avença, aquela mais benéfica ao trabalhador. No quarto e último julgado entendeu a $2^{\text {a }}$ Turma do TRT da $4^{\text {a }}$ Região ser o trabalho prestado em escritório apenas eventual, insuficiente para descaracterizar a contratação doméstica mantida com a família.

Há também situações que envolvem o que aqui se denomina relação empregatícia paralela, com dupla contratação de emprego entre os mesmos contratantes. Exemplificativamente algumas decisões proferidas em segundo grau de jurisdição trabalhista:

PROMISCUIDADE CONTRATUAL.

APLICAÇÃO DA NORMA MAIS FAVORÁVEL AO EMPREGADO. Havendo dois contratos de trabalho, mas ambos prestados em proveito da mesma pessoa e concomitantemente, impõe-se considerar único o pacto laboral, prevalecendo as condições mais benéficas ao trabalhador. (TRT, $3^{\text {a }}$ Região, $7^{\mathrm{a}}$ Turma, processo 000015191.2010.5.03.0135 RO, publicação em 18/10/2010, relator Desembargador Paulo Roberto de castro, disponível em www.trt3.jus.br, consulta em 08/09/2016).

DUPLO CONTRATO DE TRABALHO PARA A MESMA EMPRESA. Não repugna ao direito do trabalho a dupla contratação de trabalho envolvendo os mesmos empregado e empregadora, desde que para serviços e horários distintos entre si. (TRT, $3^{\mathrm{a}}$ Região, processo RO-8798/91, publicação em 24/11/1992, relator Desembargador Carlos Alberto Alves Pereira, disponível em www.trt3.jus.br, consulta em 08/09/2016).

CONTRATOS DE TRABALHO SIMULTÂNEOS - PROVA. A coexistência de dois contratos de trabalho (um de vigia noturno e outro de pedreiro, em jornada diurna) circunstância excepcional, exigindo comprovação satisfatória. Impossível reconhecê-la com base apenas no fato de ter o empregado passado a residir numa casa ao lado da construção. (TRT $3^{\mathrm{a}}$ R. - 3T - RO/1059/87 - Rel. Juiz Ney Proença Doyle - DJMG 25/09/1987).

\begin{abstract}
"DUPLO CONTRATO DE TRABALHO COEXISTÊNCIA. Admitida a coexistência de dois contratos distintos, entre empregador e empregado, há de ser rejeitado o pedidos de horas extras, por absolutamente incompatível com os dois contratos, além do que, não há prova do tempo dedicado a cada uma das atividades." (TRT $3^{\text {a }}$ R. - 5T - RO/17561/95 - Rel. Juiz João Eunápio Borges Júnior - DJMG 27/04/1996)
\end{abstract}

"DUPLA FUNÇÃO. Restando a demonstração contundente que o autor exerceu dupla função na empresa - vendedor e maloteiro - em horário diverso daquele inicialmente contratado, consubstanciando o exercício de dupla atividade, há de receber remuneração por ambas." (TRT $3^{\mathrm{a}}$ R. - $2 \mathrm{~T}$ RO/0911/95 - Rel. Juiz Hiram dos Reis Corrêa DJMG 27/10/1995).

Todas as decisões acima transcritas são relevantes para o presente estudo em decorrência do fato de ter havido o reconhecimento do paralelismo. Nos dois últimos processos imediatamente citados houve não só o reconhecimento da dupla contratação, mas, também, de efeitos jurídico-trabalhistas de ambos de modo distinto. No RO/1059/87 há a consagração da tese do paralelismo em tese, mas sem que tivesse a parte se desincumbido de seu ônus probatório. No processo RO-8798/91 se reconhece em tese o paralelismo, mas a ementa não esclarece quais os efeitos de tal constatação fática. Por fim, o primeiro caso, em que há referência expressa à promiscuidade contratual mas com o reconhecimento de um único contrato, o mais benéfico (engenheiro, in casu), por aplicação do "princípio da norma mais benéfica", conforme acórdão. ${ }^{17}$

labor como técnico reparador de linhas e engenheiro dentro de uma mesma jornada, em situação que não admite a bipartição real do contrato, acarreta a sua caracterização na forma que se apresente mais favorável ao empregado, ante $o$ princípio da norma mais benéfica, 
Depreende-se, portanto, que o reconhecimento judicial do paralelismo ou promiscuidade contratual não é garantia de percepção de direitos próprios de cada contrato mantido em concomitância, havendo soluções diferentes para contextos semelhantes.

\section{RELAÇÕES CONTRATUAIS PARALELAS NO ÂMBITO DOMÉSTICO}

A definição aqui apresentada a respeito do paralelismo contratual tem por cerne a coexistência de dupla avença laborativa entre os mesmos sujeitos contratantes. Assim, há paralelismo contratual nas situações fáticas em que trabalhador e contratante fixam entre si dois pactos jurídicos cujo objeto é o trabalho, podendo haver entre eles dois contratos de emprego (relações empregatícias paralelas) ou um contrato de emprego e outro de trabalho sem vínculo empregatício (relações trabalhistas paralelas). No que concerne ao âmbito doméstico da prestação laborativa a situação mais comum parece ser a de um vínculo empregatício celetista fixado paralelamente a um contrato de emprego doméstico. Excepcionalmente pode haver relação trabalhista paralela no âmbito doméstico, com a contratação do trabalho de diarista paralelamente a um vínculo celetista ou doméstico. Necessário, de início, fixar distinções entre empregado celetista, empregado doméstico e trabalhador doméstico diarista.

Embora não devesse o Estado fazer distinção jurídica entre empregados (pelo menos no plano da consagração de direitos mínimos) optou o Brasil, historicamente, de modo

independentemente da quantidade de horas formalmente contratadas para atuação do reclamante como Engenheiro. Assim sendo, não há dúvida de que, nos termos da bem lançada sentença de 1og grau, houve promiscuidade contratual, ante a existência de dois contratos, cuja prestação de serviços se da dava simultaneamente, sem ter como aferir e separar, cujo risco do comportamento assumido pela reclamada deve arcar, impondo-se-lhe pagar preconceituoso e absurdo, por tratar de modo diverso os trabalhadores empregados rurais (até 1972) e domésticos (até abril de 2013). Finalmente, com a Emenda Constitucional n. 72/2013 a República brasileira iniciou um processo de correção do tratamento desigual injusto que vigorou até então.

Na década de 1940, com a Consolidação das Leis do Trabalho, o Brasil perdeu a primeira oportunidade histórica de fazer justiça aos trabalhadores domésticos. Por opção preconceituosa (cor e classe social) decidiram as elites não estender aos trabalhadores domésticos os direitos consolidados, nos termos da norma contida no artigo $7^{\circ}$, alínea "a" da CLT.

A explicação para a desigualdade injusta era de que o empregador doméstico, ao contrário do que pode acontecer com o empregador celetista, não explora a atividade do trabalhador com objetivo de obtenção de ganhos econômicos no mercado. Havia, até 2013, uma inversão de valores básicos: proteção ao empregador doméstico (e não ao empregado) que, na percepção do Estado, não teria condições de cumprir as mesmas exigências legais que cumpria o empregador celetista. Não havia, portanto, reconhecimento da igualdade fática entre trabalhadores.

Felizmente a desigualdade justrabalhista não mais vigora amplamente no Brasil, tendo a OIT, por sua Convenção 189, papel decisivo na (tardia) alteração constitucional. Assim, é hoje relevante a distinção entre empregado celetista e empregado doméstico para a aplicação pontual de direitos e formalidades diferentes entre uns e outros, para o correto enquadramento sindical e,

ao autor o salário do engenheiro porque mais benéfico, qual seja, as regras específicas previstas para o Engenheiro (Lei 4.950-A/66), bem assim anotar a CTPS como Engenheiro." TRT, $3^{\mathrm{a}}$ Região, $7^{\mathrm{a}}$ Turma, processo 000015191.2010.5.03.0135 RO, publicação em 18/10/2010, relator Desembargador Paulo Roberto de castro, disponível em www.trt3.jus.br, consulta em 08/09/2016. 
principalmente, para a fixação jurídica da figura do diarista. Aqui a distinção é especialmente relevante para que haja a compreensão de relações (trabalhistas e empregatícias) paralelas no âmbito doméstico.

Dada qualquer relação jurídica de entrega de força produtiva no mercado deve o intérprete, de plano, identificar a possibilidade da existência do vínculo empregatício doméstico, vez que especial. ${ }^{18}$ Para a caracterização do emprego doméstico é necessária a confluência de oito elementos fático-jurídicos, requisitos ou pressupostos da vinculação especial.

O primeiro elemento fático-jurídico caracterizador do vínculo doméstico é finalidade não-econômica do trabalho explorado ou, nos exatos termos do artigo $1^{\circ}$ da Lei Complementar 150/2015, "serviço de finalidade não lucrativa". ${ }^{19}$ Para que haja contrato de emprego doméstico não pode haver exploração do trabalho com objetivo de ganhos econômicos no mercado (comércio, indústria, prestação de serviços, agronegócio). $\mathrm{O}$ contratante doméstico não pode objetivar ganhos econômicos diretos através da exploração de trabalho. Assim, tendem a ser pouco relevantes as tarefas do trabalhador, que será empregado doméstico (presentes todos os demais requisitos) se trabalhar em um contexto em que sua atividade não enseja ganhos econômicos ao seu contratante. De qualquer modo, caso o trabalho seja explorado com finalidade econômica, a consequência primeira, lógica e jurídica, é a inexistência do trabalho doméstico. Em uma análise posterior deverá o intérprete compreender se a relação mantida é de emprego, rural ou celetista, ou não.

O segundo elemento fático-jurídico caracterizador do vínculo doméstico é contratante pessoa física ou família, nos termos do artigo $1^{\circ}$

\footnotetext{
${ }^{18}$ A doutrina brasileira não trata expressamente da ordem de análise, s.m.j., mas a possibilidade de ocorrência de relação empregatícia doméstica deve ser vista antes mesmo da análise da existência ou não de vínculo celetista ou rural, posto ser esta relação especial mesmo após a alteração do artigo $7^{\circ}$ da Constituição da República.
}

da Lei Complementar 150/2015. Para que haja contrato de emprego doméstico não pode haver exploração do trabalho por pessoa jurídica ou por ente despersonificado. É claro que o emprego doméstico pressupõe contratante doméstico, ou seja, uma pessoa física ou uma família. Por extensão a doutrina e a jurisprudência contemplam a possibilidade de que as repúblicas de estudantes contratem trabalho doméstico.

$\mathrm{O}$ terceiro elemento fático-jurídico caracterizador do vínculo doméstico é ambiente residencial da prestação laborativa, também nos termos fixados no artigo $1^{\circ}$ da Lei Complementar $150 / 2015$. Para que haja contrato de emprego doméstico o trabalho deve ser prestado em ambiente residencial, ou ter a residência como referência básica da prestação laborativa. É claro que o emprego doméstico pressupõe contratante doméstico e ambiente doméstico da prestação. Pouco importa, aqui, se o trabalho é prestado no domicílio da família, em casa de campo, em casa de praia, em sítio ou fazenda, desde que não haja exploração de atividade econômica com o concurso do trabalhador em questão.

Os três primeiros elementos fáticojurídicos aqui vistos são considerados pela melhor doutrina requisitos especiais. Devem ser analisados em primeiro lugar. Somente se presentes todos os três primeiros requisitos é que fica o intérprete autorizado a prosseguir na análise. Caso se faça ausente qualquer dos três requisitos especiais conclui-se pela inexistência de trabalho doméstico. Presentes os três requisitos especiais depreende-se o trabalho doméstico, que será ou não emprego a depender dos demais cinco elementos fático-jurídicos. Assim, independentemente de haver ou não emprego, ou seja, de haver ou não a confluência dos demais

${ }^{19}$ A expressão, trazida da Lei 5859/1972, é pouco técnica, pois há empregadores celetistas que não exploram atividade com fins lucrativos. Assim, a essência da distinção não pode ser o lucro, mas, sim, a atividade econômica. 
cinco requisitos, estarão excluídas as possibilidades de vínculo rural ou celetista caso presentes os três especiais, vez que restará caracterizado o trabalho doméstico.

O quarto elemento fático-jurídico caracterizador do emprego doméstico é a continuidade da prestação laborativa, que afinal está objetivamente delimitada pela legislação brasileira. $\mathrm{O}$ artigo $1^{\circ}$ da Lei Complementar 150/2015 fixou que o trabalho doméstico ensejará vínculo empregatício (se presentes, é claro, os demais requisitos) se a prestação laborativa se der por mais de dois dias por semana. Distingue-se o trabalho não-eventual daquele contínuo, nos termos da lei e da melhor doutrina, pelo fato de não se pesquisar, neste caso, o evento (motivo) ensejador da contratação de trabalho (dado subjetivo), mas, sim e somente, a quantidade de dias trabalhados no curso de uma semana (dado objetivo, numérico), ou seja, mais de dois dias.

Fixado o trabalho doméstico, que não tem objetivos econômicos, que se dá em proveito de pessoa física ou família, em ambiente residencial, e entendido como contínuo o trabalho, 3, 4, 5 ou 6 dias por semana, então deve o intérprete pesquisar a existência dos elementos fáticojurídicos gerais da relação de emprego doméstico: trabalho por pessoa física, pessoalidade, onerosidade e subordinação.

Em síntese, ausente requisito especial (trabalho sem finalidade econômica, prestado à pessoa física ou família, em âmbito residencial) não haverá trabalho doméstico, devendo o intérprete pesquisar a existência ou não do vínculo rural ou do vínculo celetista. Presentes os requisitos especiais, mas ausente a continuidade, o trabalhador é doméstico, diarista, porém não é empregado, não sendo possível, neste caso, a pesquisa sobre os vínculos rural e celetista.

${ }^{20}$ BARROS, Alice Monteiro de. Curso de Direito do Trabalho. 6. ed. São Paulo: LTr., 2006, p. 353.
Feitas as necessárias conceituações e distinções é possível, agora, a análise específica do paralelismo contratual doméstico.

De início relações empregatícias paralelas, com uma avença de emprego celetista fixada concomitantemente a um contrato de emprego doméstico. Não é incomum situação fática de contratação formal doméstica que se inicia com atividades laborativas não econômicas, mas que depois sofre o acréscimo de tarefas vinculadas a um propósito econômico do empregador. São casos em que há atividade nãoeconômica na realização de tarefas diversas, mas que se combinam com outras, vinculadas ao interesse econômico do contratante. Exemplificativamente o caso de uma trabalhadora que além de cozinhar para a família, realizando as tarefas domésticas, também participa de atividade econômica comercial (bar, restaurante, pousada) de interesse dos mesmos contratantes nos finais de semana ou fora do horário de trabalho na residência. Defende-se aqui o reconhecimento do paralelismo com duplo efeito contratual, ou seja, o reconhecimento de um vínculo empregatício doméstico e de um contrato de emprego celetista.

Alice Monteiro de Barros trata do tema e oferece solução diferente daquela aqui prevista, pois sua tese era no sentido de que se houver "concomitância na prestação de serviços domésticos e em atividade lucrativa, para um mesmo credor de trabalho, prevalecerá o ordenamento jurídico que for mais favorável ao trabalhador..." 20 A solução jurídica seria o reconhecimento de um único contrato, o celetista, visto ser, ainda hoje, mesmo após a Lei Complementar 150/2015, mais favorável ao trabalhador.

Inobstante a conclusão da Prof. Alice Monteiro de Barros, a solução mais condizente com o princípio da proteção ao trabalhador é o do 
reconhecimento do duplo contrato, cada um produzindo seus efeitos próprios e, aqui, distintos.

Não chega a ser incomum situação de relação trabalhista paralela com um vínculo doméstico concomitante a um contrato de parceria rural. Como visto acima, em ementa da lavra do Prof. Dr. Luiz Otávio Linhares Renault (002932009-095-03-00-2 RO) há casos em que o caseiro do sítio de lazer, empregado doméstico, explora autonomamente, em parceria com seu empregador, pequena atividade agroeconômica. Há, nestes casos, um contrato de emprego (doméstico) paralelamente a uma contratação civil (parceria rural), o que caracteriza, nos termos aqui propostos, relações trabalhistas paralelas. Não haverá dúvidas, neste caso, de que são dois contratos concomitantes, cada um produzindo efeitos próprios e característicos, embora haja só um contrato de emprego.

Possível também, mas bem menos comum, a coexistência de uma pactuação de trabalho diarista com um contrato de emprego celetista, o que caracteriza relação trabalhista paralela. Pode-se pensar na situação fática de um trabalhador que faz a conservação e limpeza no estabelecimento comercial da pessoa física ou família e que, aos finais de semana (2 dias), desempenha tais tarefas em residência desta. Aqui haveria relação de emprego celetista em decorrência da exploração de trabalho com finalidade econômica e outro vínculo, diarista, em residência. Defende-se aqui a tese, para manter coerência, de dupla contratação, cada contrato produzindo efeitos próprios e característicos, embora haja só um contrato de emprego.

Maurício Godinho Delgado e Gabriela Neves Delgado tratam do tema em seu livro "O Novo Manual do Trabalho Doméstico”, em item denominado "Paralelismo de relações jurídicas: enquadramento". Os citados autores tratam do que aqui se denomina relações trabalhistas

${ }^{21}$ DELGADO, Maurício Godinho, DELGADO, Gabriela Neves. O Novo Manual do Trabalho Doméstico: com os paralelas e adotam a teoria esposada por Alice Monteiro de Barros. Em síntese:

De toda maneira, nesse cotejo de situações ou
relações paralelas envolvendo os mesmos atores
sociais e jurídicos, é prudente ponderar o seguinte:
uma presença significativa de exercício de atividades
efetivamente lucrativas para o tomador de serviços
em paralelo às atividades tipicamente domésticas,
terá o condão, pela lógica jurídica prevalecente no
campo do Direito do Trabalho - em que imperam os
princípios da proteção e da norma mais favorável -,
de tender a produzir o enquadramento da relação
jurídica híbrida no campo social regido pela CLT,
em detrimento daquele regulado pelas regras
especiais e mais restritivas domésticas. ${ }^{21}$

O presente estudo, por abarcar outras formas de paralelismo doméstico, insiste em solução diversa, que dê a mesma resposta para todas as situações em que há relações trabalhistas paralelas, ou seja, a afirmação do duplo contrato, com efeitos jurídicos próprios a cada um deles. Assim, uma vez reconhecido o paralelismo (ou promiscuidade) haverá, independentemente da situação fática, o reconhecimento de duplo efeito, decorrentes de dois contratos concomitantes.

\section{RELAÇÕES CONTRATUAIS PARALELAS NO MAGISTÉRIO}

A definição aqui apresentada a respeito do paralelismo contratual tem por cerne, repita-se por necessário, a coexistência de dupla avença laborativa entre os mesmos sujeitos contratantes. Assim, há paralelismo contratual nas situações fáticas em que trabalhador e contratante fixam entre si dois pactos jurídicos cujo objeto é o trabalho, podendo haver entre eles dois contratos de emprego (relações empregatícias paralelas) ou um contrato de emprego e outro de trabalho sem vínculo empregatício (relações trabalhistas paralelas).

No que concerne ao magistério superior há situações específicas de relações empregatícias

comentários aos artigos da LC n. 150/2015. São Paulo: LTr., 2016. p. 50. 
paralelas com dois vínculos empregatícios celetistas diferentes, por diferente agregação do trabalhador ao sindicato ("enquadramento sindical"), fixados concomitantemente. Há também a possibilidade da ocorrência de um vínculo empregatício celetista paralelamente a uma vinculação contratual civil, regra geral com autonomia do prestador de serviços (que é também professor) nesta relação.

Inicialmente as relações trabalhistas paralelas. Não é incomum que instituições de ensino superior se valham dos conhecimentos profissionais de seus professores para deles contratar trabalho não vinculado ao magistério. Assim, paralelamente à vinculação empregatícia celetista, cujas tarefas são aquelas próprias de professor ${ }^{22}$, advogados prestam serviços jurídicos, médicos atuam como clínicos, psicólogos atendem alunos e atuam nos setores de recursos humanos, administradores planejam estrategicamente o empreendimento, engenheiros cuidam de obras, economistas prestam consultoria, tudo isso no interesse direto e imediato daquele que, ao mesmo tempo, é seu empregador e contratante na relação civil. A distinção em face às relações de emprego que se constroem paralelamente é que o segundo contrato $^{23}$, neste caso, contempla prestação laborativa autônoma, havendo, especificamente em tais situações, relações trabalhistas paralelas.

22 "O profissional responsável pelas atividades de magistério, para fins de aplicação das cláusulas deste Instrumento, que tenha por função ministrar aulas práticas ou teóricas, ou desenvolver, em sala de aula ou fora dela, as atividades inerentes ao magistério, de acordo com a legislação de ensino" Convenção Coletiva de Trabalho SINPRO.Minas e Sindicato das Escolas Particulares de Minas Gerais, 2015-2017, Cláusula 52ª .

23 "Segundo" aqui somente para distinguir do primeiro, que é relativo ao magistério com vínculo celetista. Não necessariamente em ordem cronológica ou de importância.

${ }^{24}$ Obviamente se a relação contratual firmada formalmente em termos civilistas na verdade apenas esconde um segundo vínculo empregatício a situação fática revelará relações empregatícias paralelas ou um único contrato de emprego. Exemplificativamente: "Professor de ensino superior e de pós-graduação. Caracteriza fraude a contratação de
Poucos problemas poderão decorrer de tal paralelismo contratual trabalhista, desde que a contratação civil não seja mero veículo de fraude. ${ }^{24}$ Não haverá falar-se em direitos trabalhistas decorrentes do contrato paralelo ao magistério superior em razão da autonomia na prestação laborativa. Também não há falar-se, como regra geral, em contaminação de um pelo outro. Enquanto desenvolve tarefas específicas de sua profissão, diversas daquelas do magistério, o prestador de serviços não terá tais horas de trabalho integradas à sua jornada no emprego. De igual modo os honorários recebidos não terão natureza remuneratória. Sua CTPS trará apenas o contrato de emprego, com anotação da função de professor, sem qualquer referência à contratação civil, inobstante seu objeto seja prestação de trabalho.

Aqui interessam mais as relações empregatícias paralelas no magistério. Não é incomum que instituições de ensino superior mantenham dupla contratação empregatícia celetista com um mesmo empregado. Em tais situações haverá um contrato de emprego celetista referente às funções de professor e outra avença empregatícia também celetista para tarefas outras, administrativas ou de gestão, a cargo do mesmo empregado. Necessário identificar em qual situação a atividade administrativa ou de gestão verdadeiramente indica ou exige uma (nova)

professor de ensino superior e de pós-graduação através de dois contratos distintos: um para ministrar aulas, com a CTPS anotada, e outro para a realização de atividades de pesquisa e extensão, celebrado com a empresa constituída pelo professor para tal finalidade. O art. 207 da CR/88 expressamente determina às universidades que obedeçam "ao princípio de indissociabilidade entre ensino, pesquisa e extensão". Assim, as atividades de pesquisa, as publicações, a coordenação de disciplinas, a orientação de alunos de graduação e pós, realizadas pelo professor, eram indispensáveis à criação e à manutenção do curso de pósgraduação da reclamada, integrando, inclusive para fins das avaliações do MEC, as atividades típicas do corpo docente. Recurso desprovido. (TRT, $3^{\mathrm{a}}$ Região, $1^{\mathrm{a}}$ Turma, processo 00283-2008-007-03-00-3 RO, relatora Desembargadora Maria Laura Franco Lima de Faria, disponível em www.trt3.jus.br, consulta em 08/09/2016). 
contratação paralela ou se, ao contrário, há atividade docente na coordenação de pessoas e tarefas relacionadas ao ensino, à pesquisa ou à extensão. O parágrafo $1^{\circ}$, inciso I, da Cláusula $52^{\mathrm{a}}$ da CCT SINPRO.Minas e SINEP, exemplificativamente, parece buscar ampliar o conceito de professor fixado no mesmo diploma normativo autônomo e já anteriormente citado:

\begin{abstract}
CLÁUSULA QUINQUAGÉSIMA SEGUNDA DEFINIÇÕES E CONCEITOS.

Para efeitos deste Instrumento, considera-se:

I - Professor. O profissional responsável pelas atividades de magistério, para fins de aplicação das cláusulas deste Instrumento, que tenha por função ministrar aulas práticas ou teóricas, ou desenvolver, em sala de aula ou fora dela, as atividades inerentes ao magistério, de acordo com a legislação de ensino Parágrafo $1^{\circ}$. Considerar-se-á professor universitário o profissional habilitado ou autorizado que, além das atividades previstas no caput, também exercer as atividades que abrangem o ensino, a pesquisa, a extensão e o exercício do mandato de cargo e função afeto a estas atividades. ${ }^{25}$
\end{abstract}

A mesma CCT prevê e a dupla contratação, sendo o segundo contrato, vistas as definições acima, afeto a sindicato diverso:

CLÁUSULA NONA - DUPLA CONTRATAÇÃO. Quando, além de ministrar aulas regularmente, o professor também exercer atividade própria da categoria de auxiliar de administração escolar, não se aplicará, em relação à função de administração escolar o disposto neste Instrumento.

Parágrafo $1^{\circ}$. Devem ser feitos dois contratos de trabalhos, constar a duplicidade de atividade na carteira profissional e no registro de empregados, bem como efetuar os devidos depósitos de FGTS em contas distintas.

Parágrafo $2^{\circ}$. A rescisão apenas da parte relativa à docência não configura alteração da jornada de trabalho nem rescisão total do vínculo empregatício, no que se referir à contratação como auxiliar de administração escolar.

Parágrafo $3^{\circ}$. A rescisão apenas relativa à parte de trabalho como auxiliar não implica rescisão total do

\footnotetext{
25 Convenção Coletiva de Trabalho SINPRO.Minas e Sindicato das Escolas Particulares de Minas Gerais, 20152017, Cláusula 52a

${ }^{26}$ Particularmente defendo a tese de vigência da pluralidade sindical no ordenamento jurídico brasileiro atual, razão pela
}

contrato, nem redução de carga horária como docente, devendo, contudo, ser homologado pela entidade ou órgão competente, conforme lei, aplicando-se o previsto no parágrafo anterior.

A diferença entre ambos os contratos não está obviamente no plano do Direito Individual do Trabalho, vez que os pactos são todos celetistas, mas sim na agregação do trabalhador ao sindicato, que não é a mesma em razão de professores constituírem categoria profissional diferenciada. Vale aqui breve explanação sobre o tema da agregação do trabalhador ao sindicato.

Há diversos padrões, no mundo capitalista ocidental, de organização sindical. As principais formas de agregação dos trabalhadores ao sindicato são: por ofício ou profissão, por categoria, por empresa e por grandes ramos ou segmentos empresariais. No Brasil duas são as possibilidades, nos termos da doutrina quase unânime: categoria profissional e categoria profissional diferenciada. ${ }^{26}$

Inicialmente a regra geral brasileira, que é a do sindicato organizado por categoria profissional. É o padrão brasileiro por representar o conjunto mais significativo dos sindicatos no Brasil. A CLT, em seu artigo 511, $\S 2^{\circ}$ define a categoria profissional. Destaque para a expressão "mesma atividade econômica ou em atividades econômicas similares ou conexas." O ponto de agregação é, portanto, a vinculação dos trabalhadores em decorrência da atividade econômica preponderante de seu empregador. Maurício Godinho Delgado define:

O ponto de agregação na categoria profissional é a similitude laborativa, em função da vinculação a empregadores que tenham atividades econômicas idênticas, similares ou conexas. A categoria profissional, regra geral, identifica-se, pois, não pelo preciso tipo de labor ou atividade que exerce o obreiro (e nem por sua exata profissão), mas pela

qual não há que se falar em tal dualidade. Sobre o assunto ver ALVES, Amauri Cesar. Pluralidade Sindical: nova interpretação constitucional e celetista. São Paulo: LTr., 2015. 
vinculação a certo tipo de empregador. Se o empregado de indústria metalúrgica labora como porteiro na planta empresarial (e não em efetivas atividades metalúrgicas), é, ainda assim, representado, legalmente, pelo sindicato dos metalúrgicos, uma vez que seu ofício de porteiro não o enquadra como categoria diferenciada. ${ }^{27}$

A regra, então, é a agregação do trabalhador ao sindicato conforme a atividade econômica preponderante do seu empregador. É o que ocorre com os empregados de instituições de ensino que não constituem categoria profissional diferenciada.

Excepcionalmente contempla a legislação brasileira a agregação a sindicato organizado por ofício ou profissão. São sindicatos que agregam trabalhadores em virtude de sua profissão, independentemente da atuação econômica do empregador. São os denominados sindicatos de categoria diferenciada, como aeronautas, jornalistas, médicos, músicos e professores. Tais trabalhadores serão representados por seus sindicatos específicos independentemente daquilo a que se dedica o seu empregador. É o que ocorre com os professores, independentemente de quem seja ou o que empreenda seu empregador. A CLT trata das categorias diferenciadas em seu artigo $511, \S 3^{\circ}$.

Assim, se um empregado é contratado como professor e ao mesmo tempo executa na instituição de ensino, paralelamente, tarefas estranhas à docência, poderá ter dupla contratação, com relações empregatícias paralelas. Importante saber, em cada caso, quais são tarefas próprias da docência e quais são aquelas atividades vinculadas diretamente à administração escolar. Vale destacar, de qualquer modo, que atividades de ensino, pesquisa e extensão são atividades docentes, mesmo aquelas inerentes à coordenação ou direção acadêmica dos trabalhos.

27 DELGADO, Maurício Godinho. Curso de Direito do Trabalho. São Paulo: LTr., 2011. p. 1262.
Diante do exposto as relações empregatícias paralelas no magistério decorrem da existência de dois contratos entre os mesmos sujeitos e de dois sindicatos também distintos que concomitantemente representam o mesmo trabalhador empregado. Cada contrato terá efeitos jurídicos próprios e diversos no que concerne à normatização coletiva autônoma.

A jurisprudência do TRT da $3^{\mathrm{a}}$ Região é amplamente majoritária no sentido do reconhecimento da dupla contratação com duplo efeito jurídico:

PROFESSORA. EXERCÍCIO DE CARGO DE COORDENAÇÃO. FUNÇÃO TÍPICA DE AUXILIAR DE ADMINISTRAÇÃO ESCOLAR. As funções de coordenador não se assemelham às de professor para fins de recebimento do salário-aula base previsto na CCT da categoria, tratando-se de atividade típica de auxiliar de administração escolar. $\mathrm{O}$ próprio instrumento normativo diferencia tais ocupações, estabelecendo regimes diferenciados e dupla contratação do empregado que cumula tais encargos, não se aplicando, relativamente ao contrato de coordenação, as cláusulas previstas nas normas coletivas dos professores. (TRT, $3^{\text {a }}$ Região, $6^{\mathrm{a}} \quad$ Turma, processo 000041017.2012.5.03.0006 RO, relator Desembargador Rogério Valle Ferreira, publicação em 17/02/2014, disponível em www.trt3.jus.br, consulta em 08/09/2016).

PROFESSOR. CUMULAÇÃO DA FUNÇÃO DE COORDENADOR. DUPLA CONTRATAÇÃO. As funções de coordenador não se confundem com as de professor, sendo certo que os instrumentos normativos aplicáveis diferenciam tais ocupações, estabelecendo a necessidade de se proceder à dupla contratação do empregado que cumula tais encargos, não se aplicando, relativamente ao contrato de coordenação, as cláusulas previstas nas normas coletivas dos professores. (TRT, $3^{\mathrm{a}}$ Região, $6^{\mathrm{a}}$ Turma, processo 0001754-46.2011.5.03.0013 RO, relator Desembargador Rogério Valle Ferreira, publicação em 17/02/2014, disponível em www.trt3.jus.br, consulta em 08/09/2016).

PROFESSOR. COORDENADOR. CUMULAÇÃO DE CARGOS. RECONHECIMENTO DE VÍNCULO. Demonstrado nos autos que a autora realmente cumulava os cargos de professora e 
coordenadora de curso universitário, impõe-se o reconhecimento do vínculo de emprego na função de coordenadora adjunto de curso, em separado do contrato de trabalho de professora, como preconizam as normas coletivas dos professores e dos auxiliares de administração escolar do Estado de Minas Gerais. (TRT, $3^{\mathrm{a}}$ Região, $1^{\mathrm{a}}$ Turma, processo 0000904-83.2011.5.03.0015 RO, relator juiz convocado Eduardo Aurélio P. Ferr, publicação em 28/09/2012, disponível em www.trt3.jus.br, consulta em 08/09/2016).

\section{PROFESSOR E COORDENADOR PEDAGÓGIC}

O. ENQUADRAMENTO SINDICAL. Inexistindo nos autos provas de que a reclamante, enquanto coordenadora de curso superior, desempenhou atividades relacionadas à docência, há que se reconhecer que o contrato de trabalho mantido com a reclamada rege-se pelo instrumento normativo celebrado entre o SINEPE/SUDESTE - Sindicato dos Estabelecimentos Particulares de Ensino da Região Sudeste de Minias Gerais e o SAAE Sindicato dos Auxiliares de Administração Escolar do Estado de Minas Gerais, o qual trata dos trabalhadores que exercem cargo de Auxiliar de Administração Escolar, no qual se incluem as atividades de coordenação. (TRT, $3^{\mathrm{a}}$ Região, $6^{\mathrm{a}}$ Turma, processo 0001350-67.2010.5.03.0065 RO, relator juiz convocado Flávio Vilson da Silva Barbosa, publicação em 12/03/2012, disponível em www.trt3.jus.br, consulta em 08/09/2016).

\begin{tabular}{lcr} 
ACUMULAÇÃO & DE & \multicolumn{2}{c}{ CARGOS } \\
DE COORDENADOR DE & CURSO & E \\
DE PROFESSOR - & CONTRATOS & DE
\end{tabular}
TRABALHO DISTINTOS - VALIDADE. O professor, considerando a regulamentação própria da CLT e nos moldes em que a função vem descrita nas normas coletivas da categoria, é o "profissional responsável pelas atividades de magistério", que tem por mister ministrar aulas práticas ou teóricas ou desenvolver, em sala de aula ou fora dela, as atividades inerentes ao magistério, de acordo com a legislação do ensino. Por certo que não se inclui neste conceito o desempenho de outras atividades, tais como a de coordenação de cursos, que não se confunde com a função de docência e que terá por atribuição a de auxiliar de administração escolar, cujo contrato será regido pela norma coletiva específica dessa categoria, e não pelas normas destinadas exclusivamente aos professores. (TRT, $3^{\text {a }}$ Região, 9a Turma, processo 000062972.2013.5.03.0013 RO, publicação em 07/10/2014, relator Desembargador João Bosco Pinto Lara, disponível em www.trt3.jus.br, consulta em 08/09/2016)

Percebe-se, portanto, o paralelismo que resulta em dupla contratação, com dois registros diferentes em CTPS, dois contracheques e dois padrões remuneratórios distintos em decorrência da aplicação de instrumentos normativos diferentes. Decisão bem fundamentada em sentido contrário, embora date de 2011, deve ser destacada também em decorrência da relatoria do processo:

EMPREGADO CONTRATADO COMO
PROFESSOR QUE PASSA A TER ATUAÇÃO
CONCOMITANTE COMO COORDENADOR DE
CURSO. DUPLICIDADE DE CONTRATOS. NÃO
OCORRÊNCIA. PRESCRIÇÃO BIENAL QUE SE
AFASTA. O exercício de mais de uma função para
um mesmo empregador, de forma cumulada ou não,
no decorrer de um lapso temporal determinado ou
indeterminado, mas de forma continuada, rotineira e
em atividades diretamente relacionadas à atividade-
fim deste mesmo empregador não implica existência
de dois contratos de trabalho, ou duas prestações de
serviços entre as mesmas pessoas. Assim é que o
empregado, originalmente contratado como
professor, mas que passa, por determinado período,
a laborar também como coordenador de curso, não
pactua dois contratos distintos com a mesma
empregadora, mas tão-somente um único contrato. A
formalização de uma segunda contratação não tem o
condão de induzir a existência de um segundo
contrato. Por tal razão, não há se falar em prescrição
bienal a contar da data de cessação da segunda
atividade assumida, havendo apenas um marco
prescricional, que incide na data da ruptura
contratual. (TRT, 3 a Região, 10a Turma, processo
0000962-98.2010.5.03.0087 RO, publicação em
04/05/2011, relatora Desembargadora Taisa Maria
Macena de Lima, disponível em www.trt3.jus.br,
consulta em 08/09/2016).

Aqui a decisão privilegiou o fato de ambas as tarefas designadas ao professor, magistério e coordenação de curso, serem essenciais à concretização dos objetivos econômicos do contratante, o que, repita-se, não vem sendo observado pela jurisprudência mineira majoritária.

Assim, o duplo contrato, aqui tratado como relações empregatícias paralelas, decorre de diferente agregação sindical em relação a um mesmo trabalhador.

Alguns problemas podem advir do paralelismo empregatício no magistério. A análise será restrita à situação de dois contratos 
formais de emprego celetista distintos e concomitantes entre as mesmas partes. As situações controvertidas mais frequentes dizem respeito à sobrejornada, férias, intervalos e fraudes contra normas remuneratórias.

A opção interpretativa esposada durante todo o presente estudo foi de dissociar juridicamente ambos os contratos paralelos, preservando os efeitos próprios e específicos de cada um deles. Ocorre, entretanto, que há situações em que a preservação dos efeitos distintos deverá ser atenuada em razão de especial influência de normas jurídicas protetivas em ambos os contratos e que devem ser apreciadas concomitantemente, sob pena da perda de sua finalidade.

De início o problema da sobrejornada. Embora haja no paralelismo empregatício docente dois contratos celetistas distintos e que devem ter seus efeitos preservados enquanto avenças diversas, tal não pode se dar em relação ao limite de jornada. A situação é relativamente simples do ponto de vista fático, embora possa causar alguma perplexidade no âmbito jurídico. É que o professor, seja como docente seja nas tarefas administrativas, é uma pessoa só, protegida constitucionalmente no que concerne ao limite de jornada. Ninguém no país, tenha o cidadão um ou dois contratos, pode trabalhar mais de 8 horas diárias em favor de um mesmo contratante. $\mathrm{O}$ paralelismo contratual não possibilita, é claro, jornada lícita de 16 horas, que resultaria da equivocada soma de horas de cada contrato. $\mathrm{O}$ fato é que a Constituição da República estabelece um limite de jornada, que como tal deve ser entendido. ${ }^{28}$ Sendo assim, o empregado em paralelismo empregatício terá limite único de 8 horas diárias de trabalho e de 44 horas semanais

28 "Nunca é demais então lembrar que a melhor interpretação de uma situação concreta envolvendo disposição (diária, semanal, mensal) de trabalho é aquela que reconhece a supremacia das normas constitucionais $e$ de que trata o disposto no art. $7^{\circ}$, XIII e XIV, como limites e não como meras referências para pagamento ordinário." de disponibilidade ${ }^{29}$, devendo haver pagamento de horas extraordinárias sempre que tais limites restarem ultrapassados.

Com os mesmos fundamentos é possível afirmar que intervalos devem ser coincidentes e preservados integralmente em ambos os contratos paralelos, sem soma mas também sem redução. Isso quer dizer que a jornada limite de 8 horas deve ser observada concomitantemente em ambos os contratos e que os intervalos intrajornada e entrejornadas também serão observados em relação a cada trabalhador individualmente considerado. Vale dizer que na jornada de 8 horas deverá haver 1 hora para alimentação e descanso (CLT, artigo 71) e que entre duas jornadas deve haver pelo menos 11 horas de indisponibilidade de prestação laborativa (CLT, artigo 66).

O mesmo raciocínio acima desenvolvido vale para o período de férias, independentemente de haver ou não coincidência entre os marcos dos períodos aquisitivos e concessivos do direito ao descanso anual. Não se desconhece, novamente, a coexistência de dois contratos. Normalmente a data de admissão é diferente em cada contrato. $\mathrm{O}$ que acontece na prática é que um professor, inicialmente admitido apenas para a docência, no decorrer do pacto laboral passa a concentrar tarefas estranhas ao magistério, em data nem sempre coincidente com aquela da avença inicial. Assim, haverá dois marcos formais diferentes para observância dos períodos aquisitivos e concessivos do direito às férias. Mas é claro que tal dificuldade formal aparente não pode frustrar o instituto das férias como período de indisponibilidade de prestação laborativa. É necessária a imposição do descanso anual concomitante em ambos os contratos de emprego paralelos. A justificativa, em síntese, é a da

ALVES, Amauri Cesar. Limite constitucional de jornada, dano existencial e trabalho escravo. Revista da Faculdade de Direito do Sul de Minas, vol. 31, p. 153-186.

${ }^{29} \mathrm{Ou} 40$ horas, quando a disponibilidade semanal máxima de trabalho é limitada em tal patamar. 
preservação da essência das férias enquanto intervalo trabalhista, ou seja, direito indisponível e relacionado diretamente à saúde e à segurança do trabalhador, que recebe a precisa definição de Maurício Godinho Delgado:

[...] lapso temporal remunerado, de frequência anual, constituído de diversos dias seqüenciais, em que o empregado pode sustar a prestação de serviços e sua disponibilidade perante o empregador, com o objetivo de recuperação e implementação de suas energias e de sua inserção familiar, comunitária e política. $^{30}$

O fato de haver relações empregatícias paralelas faz com que haja influência de um contrato sobre o outro, ainda que preservada a dissociação elementar remuneratória entre ambos. A restrição do descanso pleno do trabalhador durante as férias, mantidas as atividades administrativas ensejará a aplicação das regras contidas no artigo 137 da CLT.

Para que não haja dúvidas com relação à necessidade de coincidência do período de férias em ambos os contratos paralelos, perceba-se o disposto no artigo 138 da CLT, que estabelece que “durante as férias, o empregado não poderá prestar serviços a outro empregador, salvo se este estiver obrigado a fazê-lo em virtude de contrato de trabalho regularmente mantido com aquele". Ora, se a regra celetista é de não trabalhar para outro empregador no período de descanso anual, é claro que o professor não pode trabalhar para o mesmo empregador em suas férias docentes, ainda que tenha tarefas outras a cumprir, decorrentes de um segundo contrato. As férias, por óbvio, devem ser coincidentes.

Sendo o paralelismo empregatício no magistério lícito, ou seja, havendo dupla contratação diversa decorrente de duas representações sindicais diferentes, cada contrato terá normatização coletiva própria, sem contaminação de um pelo outro. $\mathrm{O}$ mesmo não ocorre, é claro, quando o segundo contrato é firmado com agregação a sindicato diverso mas mantidas as atividades próprias de professor. As regras aplicáveis são aquelas dos artigos $9^{\circ}$ e 511 da CLT. Quando tal se dá na prática normalmente o empregador pretende afastar de parte da contraprestação devida as regras coletivas inerentes à categoria (diferenciada) dos professores, que normalmente são mais favoráveis do que aquelas avençadas com o sindicato de categoria profissional. Assim, se no segundo contrato o empregado desenvolve atividades do magistério, ainda que fora da sala de aulas, não há que se falar em paralelismo empregatício, mas em fraude às normas trabalhistas, autônomas e heterônomas.

\section{CONCLUSÃO}

Duas são as espécies do gênero relações contratuais paralelas: relações empregatícias paralelas e relações trabalhistas paralelas. A

definição desenvolvida no presente estudo a respeito do paralelismo contratual tem por cerne a coexistência de dupla avença laborativa entre os mesmos sujeitos contratantes. Assim, há paralelismo contratual nas situações fáticas em que trabalhador e contratante fixam entre si dois pactos jurídicos cujo objeto é o trabalho, podendo haver entre eles dois contratos de emprego (relações empregatícias paralelas) ou um contrato de emprego e outro de trabalho sem vínculo empregatício (relações trabalhistas paralelas). Seja qual for a situação fática, juridicamente deverá o intérprete reconhecer a dupla contratação e preservar os efeitos específicos e distintos que são próprios a cada avença mantida entre os sujeitos da relação paralela.

\footnotetext{
${ }^{30}$ DELGADO, Maurício Godinho. Curso de Direito do Trabalho. 15. ed. São Paulo: LTr., 2016. p. 1080.
} 


\section{REFERÊNCIAS}

ALVES, Amauri Cesar. Direito do Trabalho Essencial: doutrina, legislação, jurisprudência, exercícios. São Paulo: LTr., 2013.

ALVES, Amauri Cesar. Limite constitucional de jornada, dano existencial e trabalho escravo". Revista da Faculdade de Direito do Sul de Minas, vol. 31, p. 153-186.

ALVES, Amauri Cesar. Pluralidade Sindical: nova interpretação constitucional e celetista. São Paulo: LTr., 2015.

BARROS, Alice Monteiro de. Curso de Direito do Trabalho. 6. ed. São Paulo: LTr., 2010.

CASSAR, Vólia Bomfim. Direito do Trabalho. 5. ed. Niterói: Impetus: 2011.

CATHARINO, José Martins. Compêndio de Direito do Trabalho. São Paulo: Saraiva, 1982.

DELGADO, Maurício Godinho, DELGADO, Gabriela Neves. O Novo Manual do Trabalho Doméstico: com os comentários aos artigos da LC n. 150/2015. São Paulo: LTr., 2016.

DELGADO, Maurício Godinho. Curso de Direito do Trabalho. 15. ed. São Paulo: LTr., 2016.

JORGE NETO, Francisco Ferreira; CAVALCANTE, Jouberto de Quadros Pessoa. Direito do Trabalho. 6. ed. São Paulo: Atlas, 2012.

MARTINEZ, Pedro Romano. Direito do Trabalho. 6. ed. Coimbra: Almedina, 2013.

MONTOYA, Alfredo Melgar. Derecho del Trabajo. 34. ed. Madrid: Tecnos, 2013.

Recebido em: 30/09/2016

Aceito em: 31/12/2016 
